International Review of Research in Open and Distributed Learning Volume 17, Number 2

February - 2016

\title{
Connectivism in Learning Activity Design: Implications for Pedagogically-Based Technology Adoption in African Higher Education Contexts
}

Rita Ndagire Kizito

Nelson Mandela Metropolitan University, Port Elizabeth, South Africa

\begin{abstract}
This paper examines the possible characteristics and the value of designing learning activities grounded in connectivism-an emerging learning theory. It is an exploratory attempt to connect the theory to the prevailing technology adoption archetypes used in African contexts with the aim of extracting influences that could shape pedagogical technology adoption in African higher education contexts. A reflection on the process of designing learning activities that employ blogging in an experimental training intervention provides a unique context in which to try and infuse connectivist principles while outlining the challenges that surface. The questions driving the argument in this paper include: What do connectivist perspectives offer learning activity design and practice? What can the prevailing technology adoption models used in African contexts offer to learning activity design? Can we combine connectivist perspectives and Africanbased technology adoption models to inform pedagogical technology adoption in African higher education contexts? These questions are exploratory and are based on one single subjective experience of the author. They are part of an argument put forward as a proposal which is yet to be tested in practice.
\end{abstract}

Keywords: learning activity design, connectivism, pedagogically-based technology adoption, african higher education contexts

\section{Introduction}

For more than two decades, institutions have been searching for ways that could shape pedagogical technology ${ }^{1}$ adoption in African higher education contexts. These are contexts largely portrayed as having

${ }^{1}$ The term technology as used in the context of this paper refers to technological tools used for learning with blogging taken as a specific illustrative example for advancing the discussions in the paper. 
limited resources (Harley, 2011; Sapire \& Reed, 2011) and restricted access to affordable, high quality technological teaching tools (Mtebe, Dachi, \& Raphael, 2011). Despite the progress made in some institutions, there persists an incongruity between the possibilities found through research and the implementation of this research by higher education practitioners. Even after years of advocacy and advancement, pedagogically-based technology adoption is still very much in its embryonic stage in much of Africa (Hellman, 2003; Au, Lam, \& Chan, 2015; Harris, 2015).

The reasons for non-adoption are varied and depend on the teaching contexts. The organizational culture of the institutions, where staff are not willing to change their practices, can make technology integration into teaching and learning problematic (Awidi, 2008; Ramos, Tajú, \& Canuto, 2011). In addition, there are virtually "no records of success to build on" (Awidi, 2008, p. 66). A paucity of trained and motivated staff and the lack of effective technical support are also hindrances (Awidi, 2008; Harley, 2011; Sapire \& Reed, 2011; Mtebe, Dachi, \& Raphael 2011).

In a study analysing relationships across issues dealing with institutional policy, organisational culture, and e-learning use in four South African universities, Czerniewicz and Brown (2009) cite inadequacy of teaching facilities and lack of staff training as barriers to technology espousal. To that list of obstacles they add unrealistic expectations and unsustainable costs. Furthermore, they see "no evidence of critical mass being achieved" nor indication "of the requirements for scalability" (p. 130). Many technology-supported initiatives tend to remain in the early adoption stages, unable to develop from experimental to sustainable models (Harley, 2011). Socio-economic constraints and resources that could drive pedagogicallysupported teaching are also limited (Harley, 2011). There also seems to be limited understanding of technology affordances and how they could be exploited to improve teaching practice (Sapire \& Reed, 2011; Veletsianos, 2010). This could be attributed to a shortage of African-grounded research in this field (Botha et al., 2010 Harley, 2011). It could also be due to a lack of strategic direction and leadership resulting in innovations remaining unrecognised or unsupported (Ng’ambi \& Bozalek, 2013).

On the whole, African higher education is yet to develop ample, systematic, and coordinated policies and strategies that use technologies to support teaching (Sife, Lwoga, \& Sanga, 2007). Apart from infrastructural restrictions, some of the challenges experienced during technology-enhanced learning are linked to underdevelopment of learning activity design skills (Nagunwa \& Lwoga, 2012. At times, there is a focus on technology rather than on quality teaching (Mtebe, Dachi, \& Raphael, 2011). Only a few higher education practitioners are able to use technology in transformative ways (Ng'ambi, 2013). Adoption of transformative ways could bring about meaningful or "transformative learning which is an outcome of interactions with people and others" (Ng'ambi, 2013, p. 654).

With the proliferation of emerging technologies (ETs) for teaching, especially in the social networking and online space, a new learning theory-connectivism-could offer means of creating and evaluating learning in social networks where knowledge is distributed across networks of connection nodes (Siemens, 2004; Downes, 2007). The point at issue is whether connectivism can provide a theoretical lens for creating effective technology-enhanced learning environments in African higher education contexts. 
The questions driving the argument in this paper include: What do connectivist perspectives offer learning activity design and practice? What do the prevailing technology adoption archetypes used in African contexts offer learning activity design and practice? Can we combine connectivist perspectives and African-based technology adoption models to inform pedagogical technology adoption in African higher education contexts?

This paper is an epigrammatic response to these questions. First, the author's interpretation of the central principles of connectivism is presented. Second, a reflection on the author's attempt to embed connectivist principles in a training intervention for science graduate teaching assistants is presented. Blogging is used as a technology example. Third, the prevailing technology adoption archetypes used in African contexts are examined in relation to how they could be used to support the construction of connectivist learning environments. The belief is that if aligned, the possibilities and capabilities afforded by technology adoption could influence how connectivist perceptions about teaching and learning become operational. Finally, the process is appraised to identify the possibilities, problems, and limitations imposed on teaching and learning during pedagogical technology adoption.

The attempt to connect the four major strands of the paper (an African context, blogging, connectivism, and the framework for interaction) is an idealised proposition which could prove untenable if tested experimentally.

\section{What is Connectivsm?}

The theory of connectivism (Siemens, 2005) is characterised as the learning theory of the digital age. One underlying assumption in this theory is that knowledge is distributed and "can reside outside of ourselves" (Siemens, 2005, p. 8). Downes (2007) contends that "knowledge is distributed across a network of connections, and therefore learning consists of the ability to construct and traverse those networks" (para.1). This actionable knowledge is assembled from a network of connections arising from experience and interactions within a community (Garcia \& Ferreira, 2014). This is a different assumption from that used, for instance, in constructivism where knowledge is constructed by the learner (Piaget, 1976).

Collaboration whereby members of a group collectively help each other towards achieving a preestablished goal is a key concept in connectivist learning. "In this form of learning knowledge is acquired through interaction" (Garcia \& Ferreira, 2014, p. 81). Collaboration makes the process of learning efficicent and relevant because of an assumption that knowledge and expertise reside in the networks. There is room for individual and group learning in these interactions.

Siemens (2004) outlines eight principles of connectivism:

- Learning and knowledge rest in a diversity of opinions.

- Learning is a process of connecting specialized nodes or information sources. 
- Learning may reside in non-human appliances.

- Capacity to know more is more critical than what is currently known.

- Nurturing and maintaining connections is needed to facilitate continual learning.

- Ability to see connections between fields, ideas, and concepts is a core skill.

- Currency (accurate, up-to-date knowledge) is the intent of all connectivist learning activities.

- Decision-making is in itself a learning process.

The connectivist principles outlined suggest new roles for the teacher or instructor. One role involves assisting each learner to build and make the relevant connections in their learning networks. The other roles include directing students to appropriate resources and other experts, as well as creating experiences that stimulate continual learning.

Technology has a pivotal role in this learning process as it influences cognitive operations previously performed by the learner such as retrieving, organising, and storing information, through multimedia forms and platforms (Siemens, 2004; Garcia \& Ferreira, 2014). Designing connectivist learning environments that enhance interaction and cognitive engagement requires a framework.

\section{A Framework for Interaction and Cognitive Engagement in Connectivist Learning}

Wang, Chen, and Anderson (2014) have developed a framework for creating and analysing interaction and cognitive engagement in connectivist learning contexts. In this framework, the interaction occurs "between other humans and network resources and is critical for connection building and network formulation" (Wang, Chen, \& Anderson, 2014, p. 122). Learning occurs as the learner engages in different forms of network formation at the neural (cognitive), concept, and social levels (Siemens, 2005; Wang et al., 2014). For transformative learning to occur, each learner's depth of cognitive engagement should increase as the learner pushes their way through levels of interactions. The four levels of interactions are as follows: operation interaction, wayfinding interaction, sensemaking interaction, and innovation interaction (see Figure 1). 


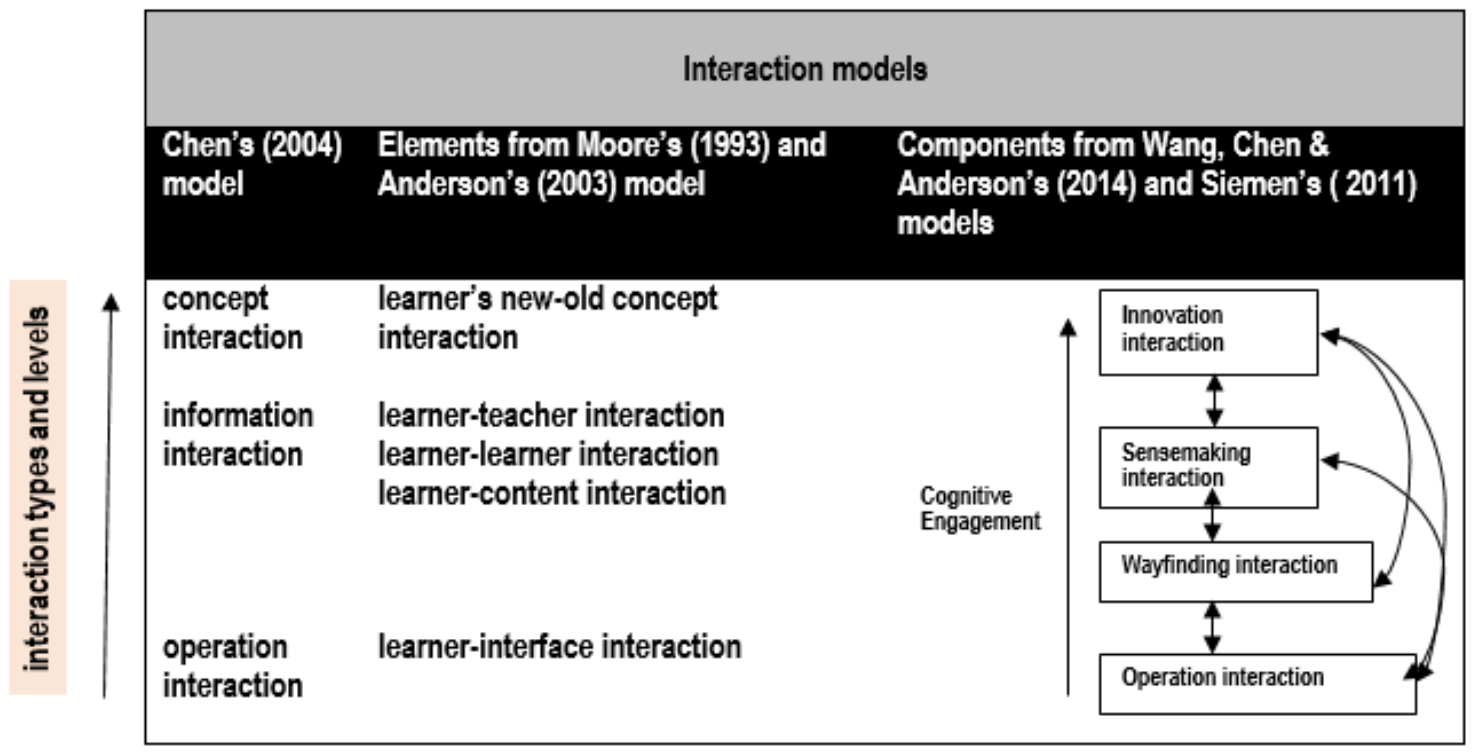

Figure 1. Framework for interaction and cognitive engagement in connectivist learning: an extension of previous models

The interactions are extensions of Moore's (1989) and Anderson's (2003) models of learner interactions in distance learning (student-teacher, student-student, and student-content). They are also an evolutional stride above Chen's (2004) hierarchical modes of instructional interaction which consists of the following: an operational interactional phase in which the student interacts with the technology; an informational interactional phase whereby the learner links with information nodes located in human and non-human resources; and a concept interactional phase where old concepts become new concepts in a process of increasing levels of abstraction and meaningful learning.

In a connectivist learning context, each learner should be assisted by a facilitator, peers, experts, and nonhuman support mechanisms to create and maintain a personal learning network (PLN) immersed in other networks. This could develop through the four phases of interactions namely operation, wayfinding, sensemaking and innovation:

- In the operational interaction phase, the learner uses technological tools such as blogs, wikis and social networks to participate in learning.

- During the wayfinding phase, learners learn how to navigate the networking terrain by identifying the right resource nodes (people or information). Actual connectivistic learning begins here in the learner-content and learner-group interactions.

- The sensemaking phase is a stage where learner-content and learner-group interactions occur at a deeper level. In this phase, the technological, social and conceptual grid is tightened as learners aggregate, make decisions, reflect, and build a coherent understanding of information collaboratively. 
- The highest level of cognitive interaction and engagement occurs at the innovation interaction stage when learners are able to create or modify artefacts, and engage deeply with others while reflecting on these artefacts.

\section{Connectivism in Learning Activity Design}

Similar to constructivism, the learner is central to the learning process in connectivism. However, the networking processes in connectivism adds a dimension to the social context in which the collaborative activity enhances knowledge construction (learning) in a slightly different way. In constructivism, learning is "determined by the complex interplay among learners' existing knowledge, the social context, and the problem to be solved" (Tam, 2000, para.14). In connectivism, the concern is more with an understanding of the distribution of expertise and intelligence over the learning network, and the role of technologies in assisting the learner to construct knowledge (Ng'ambi, 2013). In my view, the connectivist theory and the framework for interaction (from Wang et al., 2014) open up a way of thinking about the object of learning differently. The object of learning becomes distributed across human and non-human resources. This in turn affects the way one thinks about designing learning activities and how they are enacted in technology-supported learning environments.

When designing a learning activity, identifying the rationale for learning can be a challenge. Dewey's (1938) view was that the problematic or context was the driver behind the design of any learning activity. From a connectivist perspective, the driver is the activation of learner participation in interactions resulting in the formation of different types of networks (cognitive, concept, and social) supported by technology (Siemens, 2004; Wang et al., 2014). The learning activity should therefore be designed in a manner that develops, supports, and maintains network formation and human connections.

Two characteristics seem to be central to a connectivistic notion of learning activity design:

- A simulating and motivating learning activity that asks of and allows for learners to create artefacts in personal networks linked to other social networks.

- A technogically-supported environment that supports meaningful dialogue and collaboration.

In this study, an attempt is made to link the connectivist theory to the prevailing technology adoption models used in African contexts with the aim of extracting influences that could shape pedagogical technology adoption in African higher education contexts. This is done through a reflective review of the process of re-designing learning activities that use blogging in an experimental training intervention for teaching assistants. The pilot programme provides a unique context to try and infuse connectivist principles while outlining the challenges that surface during the process.

\section{The Context: a Teaching Assistant Training Programme}

The teaching assistant (TA) training programme was established in 2013 from an alliance formed between the Manufacturing, Engineering and Related Services Sector Education and Training Authority 
(merSETA) and the University of the Western Cape (UWC). The TAs who were post-graduate students in the Faculty of the Natural Sciences assist lecturers in providing additional learning support to undergraduate students enrolled in the Extended Curriculum Programme (ECP). Students in the ECP have their first year curriculum extended over two years allowing them to complete a 3-year BSc degree over a 4-year period (Table 1) for the ECP course structure. They receive tuition in mathematics, physics, life sciences and academic literacies.

Table 1

ECP Course Structure

\begin{tabular}{|c|c|c|c|c|}
\hline Academic year & Required Cou & & & \\
\hline Year 1 & $\begin{array}{l}\text { Maths150/ } \\
\text { Maths151 }\end{array}$ & Physics151 & Life Sciences 151 & $\begin{array}{l}\text { Introduction to } \\
\text { Science } 153\end{array}$ \\
\hline Year 2 & $\begin{array}{l}\text { Maths152/ } \\
\text { Statistics151 }\end{array}$ & Physics 152 & Life Sciences 152 & $\begin{array}{l}\text { Main stream } \\
\text { subject }\end{array}$ \\
\hline
\end{tabular}

The first part of the TA training programme comprised eight sessions of five hours each in which the following elements were required by participants: explore the UWC teaching and learning context; learn to design appropriate learning activities, facilitate learning, and mark and assess student work; and identify a small researchable project. Each session consisted of a face-to-face component and an online component. All of the assignments were posted on to a collaborative blog space but each participant had a personal blog space for uploading responses to the assignments. In the second part of the programme, the focus was on assisting participants to collaboratively work on a small research project. The programme was not compulsory and non-credit bearing.

An initial evaluation of the TA programme revealed that students found the blog a worthwhile tool to use in supporting learning. However, participants raised three concerns: (a) the programme workload was too demanding considering that participants were post graduate students with additional teaching roles, (b) the learning activities could have been made more practical and aligned with their TA roles, and (c) that participants did not receive sufficient feedback during the course to help them improve practice (Kizito, 2014). These issues were considered when selecting a methodological approach to use in the study.

\section{Methodological Approach}

A qualitative review approach used in this study is a reflective description of the author's attempt to use connectivist principles to re-design learning activities in the TA training programme. The approach is part of an iterative refinement process using design-based research (DBR) to improve teaching and learning practices (Kali, 2008). In the first phase of the process, the design principles are identified and articulated. The second phase involves enactment and refinement, while the third phase is about revising the pragmatic principles. This paper is a report on the first phase. 
The TA training programme has provided a unique context in which to try and infuse connectivist principles. Blogging is used as the main supportive technology. Data sources have included the design document containing the learning outcomes and the original learning activities (see Appendix), blog entries of the 11 students who participated in the first round of the programme, and 11 articles written about technology adoption in African contexts. Permission was sought from the participants to use their data. Ethical clearance to conduct the research was granted by the research committee of the university involved. The conjectures made in this study will require further exploration with more respondents to make a significant contribution to this area of research.

This review was accomplished in three stages. In the first stage, learning activities were appraised in terms of how they aligned (or not) with connectivist principles. The role of the blog in the learning transactions was accentuated. In the second stage, technology adoption archetypes (or models) emanating from African-based research were identified and possible linkages to a connectivist approach to learning activity design were made. In the third and final stage, the two have been combined to inform a process that could contribute to informing pedagogical technology adoption in African higher education contexts.

The technology adoption archetypes used in the study were identified through a Google Scholar search using keyword searches including technology adoption, technology-based learning, and African higher education. The search was restricted to the period from 2000 to 2014. About 20 articles were selected but only 11 articles have been used in the study. These articles were listed according to study title, technology archetype solution, and possible linkages to connectivism.

\section{Data Analysis}

There are two basic units of analysis: the learning activity and the technology-adoption archetypes. To address the first research question-what do connectivist perspectives offer learning activity design and practice? - Wang, Chen and Anderson's (2014) framework of the four interaction phases has been applied to one of the learning activities to establish the extent to which connectivist perspectives could be utilised. To address the second question-what do the prevailing technology adoption archetypes used in African contexts offer learning activity design and practice? - a constant-comparison approach promoted by Guba and Lincoln (1994) has been used to review the selected articles. The various categories emerging inductively through the author's interaction with the two sets of data have been used to address the third question-how can the two combine to inform the process of transforming pedagogical technology adoption in African higher education contexts?

\section{Findings}

Even though the blog was introduced to the learning environment, the modes of instruction remained largely untransformed and were predominantly affirmative (expository and demonstrative; Goguelin [1994] as cited by Garcia \& Ferreira [2014]), with facilitators mainly presenting content or demonstrating aspects in the face-to-face sessions followed with some student participation. Gogulein (1994) in Garcia

and Ferreira (2014) groups pedagogical methods into three categories: affirmative (expository and 
demonstrative), interrogative, and active. Both the affirmative and interrogative methods are strongly teacher dependent. In the expository method, learners are exposed to learning content sequenced and structured by the teacher or expert. The teacher showcases practical aspects required for competent performance in the demonstrative method. During the interrogative method the teacher probes and asks leaners to respond to pertinent questions. The active learning method is more student centred and focuses on engaging students meaningfully in learning tasks (Prince, 2004).

The TA training programme included demonstrative sections in which participants were exposed to technological tools. Participants also designed and presented short teaching segments and received feedback from the facilitators and peers in the face-to-face sessions. With very short notice, participants were expected to participate in a collaborative environment to share their assignments. The blog was mainly used as a space for depositing instructions and responses to assignments. Table 2 is a summary of the pedagogical methods used and the levels of success with the blog.

Table 2

Summary of the Pedagogical Methods Used

\begin{tabular}{|c|c|c|c|c|}
\hline Programme Learning outcome & $\begin{array}{l}\text { Teaching \& Learning Functions } \\
\text { in the foce-to-face sessions }\end{array}$ & $\begin{array}{l}\text { Teaching a Learning functions } \\
\text { the blog supported }\end{array}$ & Level of auccess with the blog & Pedagogic methods lesed \\
\hline 1. Explare the UEC context & Introduce the UWC context & $\begin{array}{l}\text { - Post assignment } \\
\text { instructions } \\
\text { - Submit ossignments } \\
\text { responses } \\
\text { - Provide feedosok }\end{array}$ & $\begin{array}{l}\text { Perticipants were sble to } \\
\text { complete their assignments } \\
\text { There were vome faolitstor and } \\
\text { peer comments }\end{array}$ & Expository \\
\hline $\begin{array}{l}\text { 2. Design on oppropriste lesrning } \\
\text { sctivity }\end{array}$ & $\begin{array}{l}\text { - Introduce principles of } \\
\text { lesrning activity design| sctus| } \\
\text { design, introduce information } \\
\text { literacy components) } \\
\text { - Participste in proctical sessions } \\
\text { involwing the introduction of } \\
\text { technologies }\end{array}$ & $\begin{array}{l}\text { - Post assignment } \\
\text { instructions } \\
\text { - Sutmit ossignments } \\
\text { responses } \\
\text { - Provide feedosck }\end{array}$ & $\begin{array}{l}\text { This assignment was not } \\
\text { completed very wel. The tseik } \\
\text { was too long snd demanding }\end{array}$ & Expository and demenotrstive \\
\hline 3. Focilitate a learning session & $\begin{array}{l}\text { - Introduce the basics of } \\
\text { presentstion } \\
\text { - Present } 15 \text { minute teaching } \\
\text { episodes } \\
\text { - Provide orsi feedbock to } \\
\text { participsnts }\end{array}$ & $\begin{array}{l}\text { - Post assignment } \\
\text { instructions } \\
\text { - Uplosd and showcase } \\
\text { participont presentations }\end{array}$ & $\begin{array}{l}\text { All participants made their } \\
\text { presentations and cotained } \\
\text { feedtack. More time was } \\
\text { required for students to } \\
\text { improve their presentatione. } \\
\text { The presentations were not } \\
\text { uplosded to the blog space. }\end{array}$ & Demonatrative \\
\hline 4. Mark and assess student work & $\begin{array}{l}\text { - Introduce the principles of } \\
\text { sssessment }\end{array}$ & $\begin{array}{l}\text { - Post assignment } \\
\text { instructions } \\
\text { - Sutmit sssignments } \\
\text { responses } \\
\text { - Provide feedosos }\end{array}$ & $\begin{array}{l}\text { Participants did not hove } \\
\text { enough time to complete the } \\
\text { assignment }\end{array}$ & Expository \\
\hline $\begin{array}{l}\text { 3. Identify a small researchebie } \\
\text { project }\end{array}$ & There wBs no time to complete th & szsignment & & \\
\hline
\end{tabular}

\section{An Analysis of Student Responses in their Blogs}

On analysing student responses to the activities in the programme it was evident that the way the learning assignments had been designed did not stimulated sufficient interest or motivation. Nine (81\%) of the 11 participants completed the first assignment, while eight (73\%) completed the second and third assignments. There were neither blog posts nor responses for the fourth and fifth assignments. Facilitator feedback was only provided for the first assignment. Peer commentaries were minimal with only three participants (27\%) making attempts to comment on other participant blogs. Low participation could attributed to the fact that the programme was not compulsory and there were no credits nor incentive attached to TA participation. 
One of the tasks (Task 1a) in the first assignment was the following:

Briefly describe your teaching context by identifying factors which characterize teaching and learning at UWC. After writing your description, solicit input and comments from one colleague (a TA). Also comment on one other TA description.

The expectation was that participants would work together to identify factors that characterized teaching and learning unique to the UWC context and then use the blog to come to a shared understanding of teaching and learning at UWC.

There were three categories of responses: those viewing the context in terms of how they approached teaching, those who rightly identified UWC factors influencing the teaching and learning context, and those who combined both perspectives. Four of the respondents provided descriptions of how they approached teaching such as Respondent 1 who stated that, "when I develop a lesson plan outcomes for a certain topic, I try to apply the skill levels outlined by Blooms' taxonomy and build activities that can stimulate student understanding." To them, the context seemed to be a manifestation of individual actions. Three respondents appropriately outlined UWC factors that shaped the UWC teaching and learning context as exhibited in their responses. Respondent 5 stated that, "The teaching method aims to ensure that the classroom is an interactive learning environment and encourages students to engage with the course materials”. Respondent 6 stated that, "Alignment of Graduate attributes is one of the factors." Respondent 7 stated that, "building leadership and collaborative skills is important in this module." The last respondent (Respondant 8) had a combination of university-led and individual contributions: "I see my job as trying to cultivate the work ethos I needed to posses to complete my degree. ... Teaching and learning at UWC is defined by the charter of UWC graduate attributes." Had there been sufficient time, the responses could have formed the basis for further exploration within the technology-enhanced learning environment.

\section{Levels of Interaction}

A mapping of the interaction developments for one task to Wang, Chen and Anderson's (2014) framework revealed that only the first level of interactions were being addressed (see Table 3). Not enough scaffolding and feedback was evident in the blog space. The peer support was not enough encouraged and enabled. In short, not enough was done to build a collaborative and learning community. The same arguments could be applied to all the tasks the participants completed. On the whole, there were too many tasks with no underlying theory holding the tasks together.

Table 3

Levels of Interaction in One Task Based on Wang, Chen, and Anderson's framework (2014) 


\begin{tabular}{|ll|}
\hline Types of Interaction & Evidence in the blog space \\
\hline Innovation interaction & There was no evidence of genuine innovation and artefact creation \\
& resulting from the interactions. \\
Sensemaking interaction & There was no evidence of meaningful sense making in terms of \\
& sharing, filtering and aggregating information. Participants could have \\
& produced the same assignments without the blog. \\
Wayfinding interaction & There was evidence of some form of orientation expressed as \\
& instructions, but very little scaffolding and feedback. \\
Operation interaction & There was evidence of personal learning environment formation in \\
& terms of the personal blogs created by the participants.
\end{tabular}

The framework for interaction and cognitive engagement provided a structure for analysing interactions and a possible unifying theory. The author felt this could be better achieved in the broader context of pedagogic technology adoption in African learning environments to make the adaptation process more meaningful. The next section is an exploration of that process.

\section{Some Pedagogical Technology Adoption Models in African Context}

The studies involving pedagogical technology adoption models reviewed here are analysed in terms of how they could contribute to two aspects of potential connectivistic learning activity design: (a) creation of learning environments to support technologically-enhanced collaboration and (b) the design of learning activities having the potential to stimulate meaningful dialogue and learning in connectivistic environments.

The studies were varied in their foci of exploration. Some of them focussed on infrastructural requirements (Awidi, 2008; Singh, 2011; Nagunwa \& Lwoga, 2012) while others concentrated on processes needed to support (Mtebe, Dachi, \& Raphael, 2011; Adedoja, Adelore, Egbokhare, \& Oluleye, 2013) and sustain pedagogic technology adoption (Harley, 2011). In these deliberations, the role of institutional culture was underscored (Czerniewicz \& Brown, 2009; Harley, 2011). Inevitably, there were studies that attended to both aspects such as Singh (2011). Of particular interest to this study are the studies that addressed practical issues of adopting technologies in African contexts (Adedoja et al., 2013; Roberts \& Vänskä, 2011; Rambe \& Ng'ambi, 2014). Most profound was the study with an actual model for learning activity design (Ng'ambi, 2013).

Table 4 summarises five studies that could contribute to the creation of learning environments to support technologically-enhanced collaboration and network formation. Technology adoption works better in environments where there is a supportive infrastructure, clear policies, strategies, and buy-in from management (Awidi, 2008; Singh, 2011; Nagunwa \& Lwoga, 2012). However, being cognisant of the role of staff mind-sets about technology adoption processes is critical to successful adoption (Mtebe et al., 2011). A collegial environment where academics are allowed to innovate and experiment is crucial (Czerniewicz \& Brown, 2009). In addition opportunities for both academic and technical staff training are limited (Awidi, 2008; Mtebe et al., 2011; Nagunwa \& Lwoga, 2012).

Table 4 
Studies that Could Contribute to Supporting Technologically-Enhanced Collaboration and Network Formation

\begin{tabular}{|c|c|c|}
\hline Study & Technology adoption archetype solutions & Linkages to Connectivism \\
\hline $\begin{array}{l}\text { (Awidi, 2008). Developing an e-learning } \\
\text { strategy for public universities in Ghana }\end{array}$ & $\begin{array}{l}\text { A systems approach with an e learning } \\
\text { strategy where there are clear e learning } \\
\text { goals, policies and processes and schedules } \\
\text { for the implementation phases. }\end{array}$ & $\begin{array}{l}\text { Important aspects to overcoming barriers } \\
\text { of adoption include buy-in from } \\
\text { management and the importance of staff } \\
\text { training }\end{array}$ \\
\hline $\begin{array}{l}\text { (Singh, 2011). An online abstract } \\
\text { mentoring programme for junior } \\
\text { researchers and healthcare professionals }\end{array}$ & $\begin{array}{l}\text { Investment in a support structure which } \\
\text { involves the formation of a project team, } \\
\text { identification of mentors, resources such } \\
\text { as toolkit or handbook and collaboratively } \\
\text { developed guidelines }\end{array}$ & $\begin{array}{l}\text { The design of: (a) practical, targeted tasks } \\
\text { in which participants "actively reflect on } \\
\text { experience, rather than receive } \\
\text { disembodied knowledge in workshops and } \\
\text { online training" (Singh, 2011, p.240); (b) a } \\
\text { peer review process. }\end{array}$ \\
\hline $\begin{array}{l}\text { (Mtebe, Dachi \& Raphael, 2011). } \\
\text { Integrating ICT into teaching and learning } \\
\text { at the University of Dar es Salaam. }\end{array}$ & $\begin{array}{l}\text { Capacity building using a standardized } \\
\text { course design template. }\end{array}$ & $\begin{array}{l}\text { Being cognisant of the role of: (a) existing } \\
\text { staff mind-sets about technology adoption } \\
\text { processes; (b) limitations of the } \\
\text { infrastructure adoption barriers such as } \\
\text { limited LAN connectivity and disruptions of } \\
\text { power supply (load shedding). }\end{array}$ \\
\hline $\begin{array}{l}\text { (Naguwa \&. Lwoga, 2012). Developing } \\
\text { eLearning technologies to implement } \\
\text { competency based medical education: } \\
\text { Experiences from Muhimbili University of } \\
\text { Health and Allied Sciences/ }\end{array}$ & $\begin{array}{l}\text { A 5-step implementation process including } \\
\text { awareness building, improvement of } \\
\text { infrastructure, development of policies, } \\
\text { selection and appropriation of } \\
\text { technologies, training of staff and } \\
\text { students. }\end{array}$ & $\begin{array}{l}\text { Availability of training for all involved and } \\
\text { competent technical staff to support } \\
\text { project. }\end{array}$ \\
\hline $\begin{array}{l}\text { (Czerniewicz \& Brown, 2009). A study of } \\
\text { the relationship between institutional } \\
\text { policy, organizational culture and e- } \\
\text { learning use in four South African } \\
\text { Universities. }\end{array}$ & $\begin{array}{l}\text { Adoption of technologies is influenced by } \\
\text { the e-learning policy and organization } \\
\text { culture such as: (a) C-U-Collegium (with } \\
\text { loose e-learning policy and a collegium } \\
\text { organizational culture); (b) A-S and B-S } \\
\text { Corp (with structured e-learning policies } \\
\text { and corporate organization cultures); and } \\
\text { (c) D-U Bur (with an unstructured e- } \\
\text { learning policy and a bureaucratic } \\
\text { organization culture). }\end{array}$ & $\begin{array}{l}\text { The unstructured collegial type had reports } \\
\text { of more and varied instances of e- } \\
\text { technology adoption and use. }\end{array}$ \\
\hline
\end{tabular}

Studies related to the process of learning activity design which could stimulate meaningful dialogue and learning are presented in Table 5 . One has to be cognisant of "trade-offs between extra workload and the educational benefits" (Harley, 2011, p. 224) when adopting the new technologies. The initial inputs in the re-design process must be weighed in terms of later potential benefits. The value of technology-enhanced activities to participants should be balanced with ease of technology use (Adedoja et al., 2013).

Table 5

Studies Related to Learning Activity Design 


\begin{tabular}{|c|c|c|}
\hline Study & Technology adoption archetype solutions & Linkages to Connectivism \\
\hline $\begin{array}{l}\text { (Singh, 2011). An online abstract } \\
\text { mentoring programme for junior } \\
\text { researchers and healthcare professionals }\end{array}$ & $\begin{array}{l}\text { Investment in a support structure which } \\
\text { involves the formation of a project team, } \\
\text { identification of mentors, resources such } \\
\text { as toolkit or handbook and collaboratively } \\
\text { developed guidelines }\end{array}$ & $\begin{array}{l}\text { The design of: (a) practical, targeted tasks } \\
\text { in which participants "actively reflect on } \\
\text { experience, rather than receive } \\
\text { disembodied knowledge in workshops and } \\
\text { online training" (Singh, 2011, p.240); (b) a } \\
\text { peer review process. }\end{array}$ \\
\hline $\begin{array}{l}\text { (Ramos, Taju \& Canuto, 2011). Promoting } \\
\text { distance education in higher education in } \\
\text { Cape Verde and Mozambique, }\end{array}$ & $\begin{array}{l}\text { International collaboration in training and } \\
\text { research and using international experts to } \\
\text { assist with the tutoring and providing } \\
\text { feedback. }\end{array}$ & $\begin{array}{l}\text { A practical operational model of delivery } \\
\text { with a mixture of face-to-face components } \\
\text { (at the beginning and at the end of the } \\
\text { programme) together with online } \\
\text { components interspersed across the } \\
\text { delivery time. More time is allocated to } \\
\text { artefact creation. }\end{array}$ \\
\hline $\begin{array}{l}\text { (Rambe \& Ng'ambi, 2014). Learning with } \\
\text { and from Facebook: Uncovering pover } \\
\text { symmetries in educational interactions. }\end{array}$ & $\begin{array}{l}\text { Awareness of the differentiated interaction } \\
\text { patterns that might result because of } \\
\text { gender as women prefer private spaces } \\
\text { while men dominate public spaces. }\end{array}$ & $\begin{array}{l}\text { Paying particular attention to "potential } \\
\text { violations of individual privacy" (Rambe \&. } \\
\text { Ng'ambi, 2014, p. 325), and gender } \\
\text { preferences and influences. }\end{array}$ \\
\hline $\begin{array}{l}\text { (Adedoja, Adelore, Egbokhare \&. Oluleye, } \\
\text { 2013) Learner Acceptance of the use of } \\
\text { Mobile Phones to Deliver Tutorials in a } \\
\text { Distance Learning Context: A case Study at } \\
\text { the University of lbadan, }\end{array}$ & $\begin{array}{l}\text { Preconditions for successful } \\
\text { implementation include technical support, } \\
\text { capacity of learning activity designers and } \\
\text { developers and knowledge of data costs } \\
\text { faced by students. }\end{array}$ & $\begin{array}{l}\text { Paying attention to ease of use of the } \\
\text { technology and the value of technology- } \\
\text { enhanced activities to participants. }\end{array}$ \\
\hline $\begin{array}{l}\text { (Roberts \& Vänska, 2011). Challenging } \\
\text { assumptions: Mobile Learning For } \\
\text { Mathematics Project in South Africa. }\end{array}$ & $\begin{array}{l}\text { Reveals that it is possible to use devices } \\
\text { accessible to learners (such as mobile } \\
\text { phones) in formal learning. Stresses the } \\
\text { value of public-private partnerships to } \\
\text { bring about technology adoption. }\end{array}$ & $\begin{array}{l}\text { There are possible models of use in } \\
\text { resources restricted environments } \\
\text { (individually owned and the shared or } \\
\text { borrowed option). }\end{array}$ \\
\hline $\begin{array}{l}\text { (Harley, 2011).Insights from the Health } \\
\text { OER Inter-institutional Project }\end{array}$ & $\begin{array}{l}\text { Sustainability of technology adoption is } \\
\text { only possible with credibility and viability. } \\
\text { He stresses the importance of institutional } \\
\text { autonomy and the need for institutions to } \\
\text { take up ownership of the technology- } \\
\text { adoption projects. }\end{array}$ & $\begin{array}{l}\text { One has to be cognisant of "trade-offs } \\
\text { between extra workload and the } \\
\text { educational benefits" (Harley, 2011, p. } \\
224 \text { ) when adopting the new technologies. }\end{array}$ \\
\hline $\begin{array}{l}\text { (Ng'ambi, 2013). Effective and ineffective } \\
\text { uses of emerging technologies: Towards a } \\
\text { transformative pedagogical model. }\end{array}$ & $\begin{array}{l}\text { Dichotomy between what the institutions } \\
\text { have and what the students are using. Not } \\
\text { enough evidence for transformation. } \\
\text { Context restrains adoption and lack of } \\
\text { guidance. Effective use is routed in the } \\
\text { context. }\end{array}$ & $\begin{array}{l}\text { Ng'ambi (2013, p. 659).) introduces a 5- } \\
\text { phase pedagogical guidelines (a) establish } \\
\text { educational goal-object of learning activity; } \\
\text { (b) phase } 1 \text { should lead to the creation of } \\
\text { an artefact (individually or collaboratively); } \\
\text { (c) students present outcome of phase } 2 \text {; } \\
\text { (d) students reflect on the presentation } \\
\text { (phase } 3 \text { ) and artefact design (phase } 2 \text { ) and } \\
\text { obtain visible feedback (e) students vorite } \\
\text { and submit a reflective essay /assignment } \\
\text { based on the assigned task. }\end{array}$ \\
\hline
\end{tabular}

A practical operational model of delivery with a mixture of face-to-face components (at the beginning and at the end of the programme) together with online components interspersed across the delivery time (Ramos et al., 2011) is a good model for programmes such as the TA programme where actual learning time is limited. Where resources are scarce, there is the option of sharing or allowing participants to borrow rather than own devices (Roberts \& Vänskä, 2011). The shift in learning activity design is towards practical, targeted tasks in which participants "actively reflect on experience, rather than receive disembodied knowledge in workshops and online training" (Singh, 2011, p. 240). Vital to this process is the creation of an effective peer review process (Singh, 2011) and a focus on artefact creation (Ramos et al., 2011: Ng'ambi, 2013).

Ng'ambi (2013, p. 659) has introduced a 5-phase learning activity design process with elements which could be adapted in the TA training programme: 
$\checkmark \quad$ Phase 1-Establish an educational goal (object of learning activity);

$\checkmark$ Phase 2-Creation of an artefact (individually or collaboratively);

$\checkmark \quad$ Phase 3-Students present outcome of Phase 2;

$\checkmark \quad$ Phase 4-Students reflect on the presentation (Phase 3) and artefact design (Phase 2) and obtain visible feedback

$\checkmark$ Phase 5 -Students write and submit a reflective essay or assignment based on the assigned task.

In the next two sections the author elaborates on how the blog-supported learning activities in the TA training programme have been re-designed as a part of a connectivist learning context and how this could be construed as one_mechanism for pedagogical technology adoption in African higher education contexts.

\section{The Re-Configured TA Training Programme}

The TA training programme has now been re-configured to involve two learning activities encompassing shorter learning tasks with more time allocated to each task. The first learning activity involves the design and development of a tutorial learning activity in one of the ECP courses and is compulsory for all participants. This activity, which runs over a 4-week period, includes both individual and collaborative tasks (the majority of which are completed online). To link the assignments to practice, the TAs are given an experiential footing for understanding UWC contextual issues that shape teaching and learning, as they develop one tutorial activity in a real or simulated teaching context. Participants have to present the task, mark and assess actual student work, and reflect on how their tutorial activities could be improved for effective learning delivery. In the second optional learning activity, TAs work collaboratively on a small teaching and learning research project of their choice in a seminar-like environment. The TAs have 12 weeks to work on these group projects and are required to produce a conference presentation, poster, or paper.

Prior to the beginning of the TA training, facilitators are introduced to the programme structure, to connectivism, to blog technology, and to what they are expected to do as facilitators. All the sessions are designed around learning tasks related to learning activity design and delivery. Students are presented with these tasks as challenges they need to address. They are directed to sets of initial learning resources but are expected to find their own additional resources. Facilitators are expected to assist students navigate the blog terrain by providing information, scaffolding, and feedback to student contributions. Each of the two main programme learning activities begins with a contact session to discuss the work to be done and ends with another contact session to present and discuss work completed.

Connectivism is used as a unifying underlying theory with three of its principles functioning as major tenets for this programme (Siemens, 2004): 
- Learning and knowledge rests in a diversity of opinions, in both human and non-human resources.

- Learning is a process of connecting specialized nodes or information sources. It is critical that students build skills to discern what is important and are able to make appropriate connections as they construct their individual networks while learning.

- Nurturing and maintaining connections is needed to facilitate continual learning at a personal, social, and technological level.

Using the framework for interaction and cognitive engagement in connectivist learning contexts, students will be led through the four interaction levels, operation, wayfinding, sense-making, and innovation,as they work towards developing the two artefacts. The first artefact is a tutorial activity. The second artefact is a collaboratively developed research project. Ng'ambi's (2013) 5-phase process is used to operationalise the process.

Included in the first session are practical introductions to blogging for participants and a simple online peer review mechanism for evaluating the completed artefacts. The peer evaluative activity is a simple online rubric allowing participants to evaluate each other's artefacts in an objective manner. The assessment criteria for each learning activity will be jointly developed by the facilitators and participants. The evaluation process will be anonymous to avoid bias. Participants will be given guidelines to ensure that online etiquette is followed and personal boundaries are respected. Figure 2 is an illustration of the programme operational model for each learning activity.

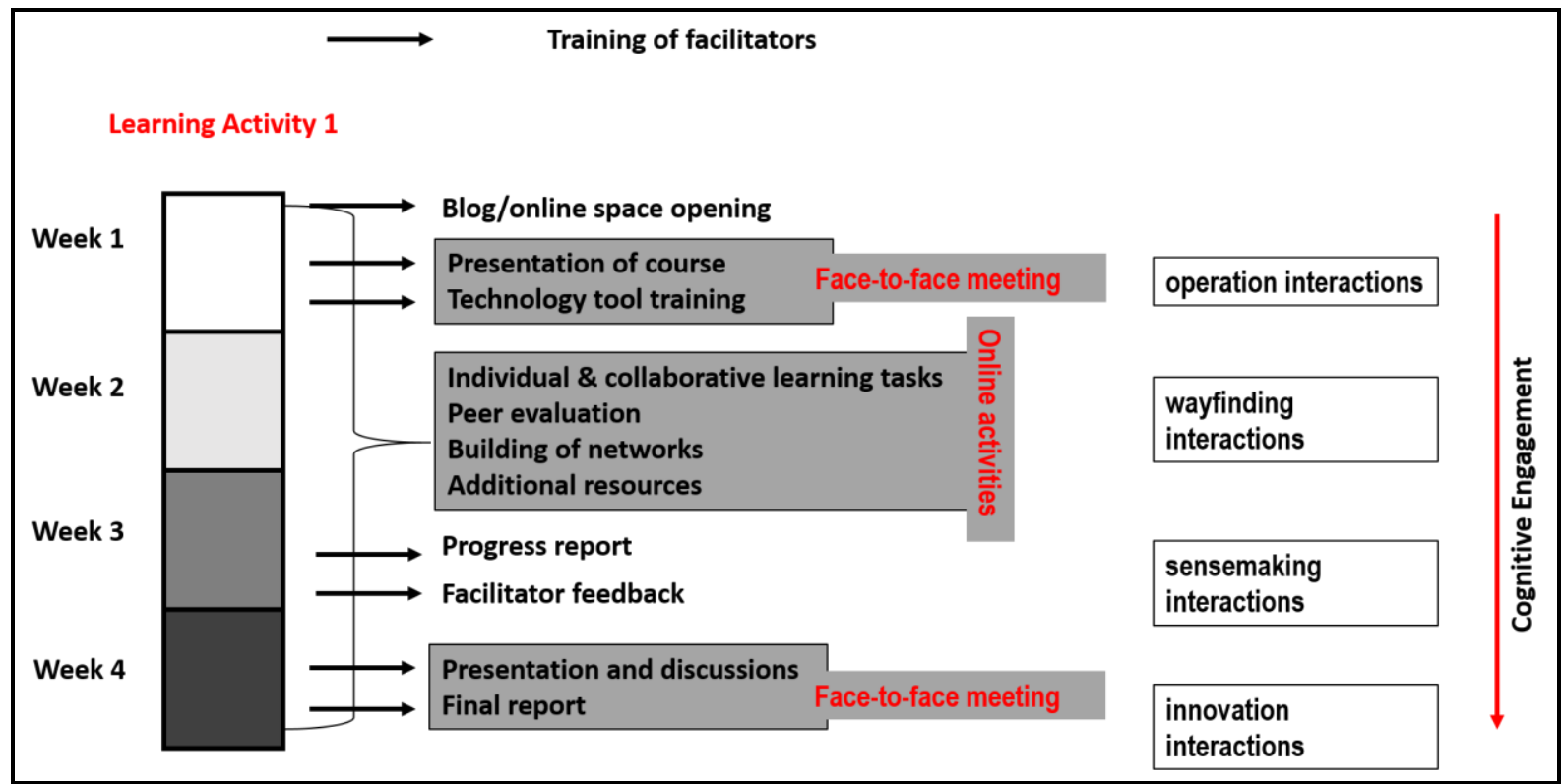

Figure 2. Operational model for a learning activity 
Each iteration of the TA training programme will be followed by an analysis of evaluation data and refinement to its design based on the outcomes of the analysis. Data sources will include the following: the created artefacts, peer evaluation data gathered in the blog space, facilitator and participant reflective contributions to the blog space, and the author's reflective journal with remarks about events taking place during the training session.

\section{Implications for Pedagogically-Based Technology Adoption in African Higher Education Contexts}

Although this is the beginning of the re-design of a programme and the model has yet to be fully tested, the process has shed some light on what could lead to successful pedagogically-based technology adoption in an African higher education context. These considerations could also be applied to the Latin American and Caribbean regions.

First of all, the chances for successful adoption are reduced if there is no clear strategy for adoption, with provision for a supportive infrastructure and a maintenance plan backed by the institution (Awidi, 2008; Singh, 2011; Nagunwa \& Lwoga, 2012). Factors which could diminish the uptake of a programme have to be considered, and responses to challenges explored, prior to adoption. For example, in the case of this TA training programme, there was no real consideration of the workload of the participants (the TAs) or the facilitators prior to its adoption. Another limiting factor was the lack of a policy guiding its implementation. Issues such as where the programme would fit in the faculty time table or how the facilitators were to be remunerated were not considered beforehand. Issues of successful uptake and scalability as demonstrated by the mobile learning project (Roberts \& Vänskä, 2011) are possible only if there is proper planning and funding to sustain and maintain a programme. For this particular programme, access to the technology was not a real barrier as was indicated in some earlier studies (Mtebe et al., 2011).

Second, the central role of the facilitators (or instructors) cannot be over-emphasized. It is important to understand staff attitudes to any technology adoption process as they are the ones responsible for maintaining and sustaining the project. Czerniewicz and Brown (2009) demonstrate that a collegial rather than a strictly bureaucratic environment will help innovations thrive. Staff and participant training is critical (Awidi, 2008; Mtebe et al., 2011; Nagunwa \& Lwoga, 2012). That is why in the operational model of learning activity design (Figure 2), the first task is staff training.

Third and lastly, the most important contribution to pedagogical technology adoption emanating from this study is an exploration of how connectivism as a theory could be used to transform learning activity design. The theory posits that learning and knowledge is distributed in both human and non-human resources and it is the notion of connectivity. However, from a learning design perspective this emerging theory introduces a dimension for inclusion of a digital networking component which makes it more suited to the design of technology-enhanced learning environments than the other dominant learning theories (behaviourism, cognitivsm, and constructivism). Wang, Chen and Anderson's (2014) framework 
for creating and analysing interaction and cognitive engagement in connectivist learning contexts can be used to both design and analyse learning interactions. Together with Ng'ambi's (2013) process, the framework can be used to structure and operationalise learning activity design such that the learning tasks are practical, aligned with professional roles but are also cognitively challenging. Furthermore, opportunities for peer assessment and facilitator feedback are critical.

Can we combine connectivist perspectives and African based technology adoption models to inform pedagogical technology adoption in African higher education contexts? Yes, the linkages between Africanbased technology adoption models to connectivism present very fundamental issues about design, the models that can be used, and what one should be aware of during the design and delivery processes. The first requirement is in ensuring that there is an infrastructure to support technologically-enhanced collaboration and individual learning. A connectivistic perspective offers the second requirement-that there is an underlying theory to buttress and support design the provision of learning activities having the potential to stimulate meaningful dialogue and learning. The test as to whether the emerging connectivistinspired model is flexible enough to adjust to diverse local contexts and levels of technological infrastructure or institutional culture is yet to be tested. The implications for applicability can only be fully drawn after that exercise is carried out in at least one context.

This paper is just a proposition which will still need to be tested and either accepted or rejected.

\section{References}

Adedoja, G., Adelore, O., Egbokhare, F., \& Oluleye, A. (2013). Learners' acceptance of the use of mobile phones to deliver tutorials in a distance learning context: A case study at the University of Ibadan. The African Journal of Information Systems, 5(3), 80-93.

Anderson, T. (2003). Modes of interaction in distance education: Recent developments and research questions. In M. G. Moore \& W. G. Anderson (Eds.) Handbook of distance education (pp. 129144). Mahwah, New Jersey: Lawrence Erlbaum Associates, Inc.

Au, M., Lam, J., \& Chan, R. (2015). Social media education: Barriers and critical issues. In K.C. Li, T.L Wong, S.K.S. Cheung, J. Lam \& K.K. Ng (Eds.). Technology in education: Transforming educational practices with technology (pp. 199-205). Berlin, Heidelberg: Springer.

Awidi, I. T. (2008). Developing an e-learning strategy for public universities in Ghana. Educause Quarterly, 31(2), 66.

Botha, A., Makitla, I., Ford, M., Fogwill, T., Seetharam, D., Abouchabki, C., Tolmay, JP., \& Oguneye, O. (2010, August/September). The mobile phone in Africa: Providing services to the masses. Paper presented at the CSIR 3rd Biennial Conference: 2010 Science Real And Relevant CSIR International Convention Center, Pretoria, South Africa. 
Chen, L. (2004). A hierarchical model for student and teacher interaction in distance learning. Distance Education in China, (05), 24-28.

Czerniewicz, L., \& Brown, C. (2009). A study of the relationship between institutional policy, organisational culture and e-learning use in four South African universities. Computers \& Education, 53(1), 121-131.

Dewey, J. (1938). Experience and education. New York, NY: Macmillan.

Downes, S. (2007, February 3). What connectivism is [Web log post]. Retrieved from http://halfanhour.blogspot.com/2007/02/what-connectivism-is.html

Garcia, L., \& Ferreira, M. J. (2014). The impact of chaos and connectivism in the collaborative/cooperative learning. Research Journal in Organizational Psychology and Educational Studies (RJOPES), 3(2), 76.

Guba, E. G., \& Lincoln, Y. S. (1994). Competing paradigms in qualitative research. Handbook of Qualitative Research, 2, 163-194.

Harley, K. (2011). Insights from the Health OER inter-institutional project. Distance Education, 32(2), $213-227$.

Harris, J. U. (2015). The promise, prospects and challenges of information communication technology (ICT) utilization in African educational systems: Continental, national and institutional realities. In C.U. Nwokeafor (Ed.). Information communication technology (ICT) integration to educational curricula: A new direction for Africa (pp. 99-118). Lanham, Maryland: University Press of America.

Hellman, J. A. (2003). The riddle of distance education: Promise, problems and applications for development. Geneva, Switzerland: United Nations Research Institute for Social Development.

Kali, Y. (2008). The design principles database as a means for promoting design-based research. In A. E. Kelly, R. A. Lesh, \& J. Y. Baek (Eds.). Handbook of design research methods in education: Innovations in science, technology, engineering, and mathematics learning and teaching (pp. 423-438). Milton Park, Oxford: Routledge.

Kizito, R (2014, September). Using the blog to enhance teaching assistant competence in undergraduate science teaching. Paper presented at the 8th Annual Teaching \& Learning Higher Education Conference,UKZN Edgewood Campus.

Moore, M. G. (1989). Three types of interaction. American Journal of Distance Education, 3(2), 1-7. 
Moore, M. (1993). Theory of transactional distance. In D. Keegan (Ed.). Theoretical principles of distance education (p. 22-38). London: Routledge.

Mtebe, J. S., Dachi, H., \& Raphael, C. (2011). Integrating ICT into teaching and learning at the University of Dar es Salaam. Distance Education, 32(2), 289-294.

Nagunwa, T., \& Lwoga, E. T. (2012). Developing eLearning technologies to implement competency based medical education: Experiences from Muhimbili University of Health and Allied Sciences. International Journal of Education and Development using ICT, 8(3).

Ng'ambi, D. (2013). Effective and ineffective uses of emerging technologies: Towards a transformative pedagogical model. British Journal of Educational Technology, 44(4), 652-661.

Ng'ambi, D., \& Bozalek, V. (2013). Editorial: Emerging technologies and changing learning/teaching practices. British Journal of Educational Technology, 44(4), 531-535.

Piaget, J. (1976). Piaget’s theory. Berlin, Heidelberg: Springer.

Prince, M. (2004). Does active learning work? A review of the research. Journal of Engineering Education, 93(3), 223-231.

Rambe, P., \& Ng'ambi, D. (2014). Learning with and from Facebook: Uncovering power asymmetries in educational interactions. Australasian Journal of Educational Technology, 3o(3), 312-325.

Ramos, F., Tajú, G., \& Canuto, L. (2011). Promoting distance education in higher education in Cape Verde and Mozambique. Distance Education, 32(2), 159-175.

Roberts, N., \& Vänskä, R. (2011). Challenging assumptions: Mobile learning for mathematics project in South Africa. Distance Education, 32(2), 243-259.

Sapire, I., \& Reed, Y. (2011). Collaborative design and use of open educational resources: A case study of a mathematics teacher education project in South Africa. Distance Education, 32(2), 195-211.

Siemens, G. (2005, January, 01). Connectivism: A learning theory for the digital age. International Journal of Instructional Technology and Distance Learning (ITDL). Retrieved from http://er.dut.ac.za/bitstream/handle/123456789/69/Siemens 2005 Connectivism A learning theory for the digital age.pdf?sequence $=1$ '

Siemens, G. (2005, August 10). Connectivism: Learning as network-creation. International Journal of Instructional Technology and Distance Learning (ITDL). Retrieved from http://www.elearnspace.org/Articles/networks.htm. 
Siemens, G. (2011). Orientation: Sensemaking and wayfinding in complex distributed online information environments (Doctoral dissertation, University of Aberdeen). Retrieved from http://ethos.bl.uk/OrderDetails.do?uin=uk.bl.ethos.558600

Sife, A., Lwoga, E., \& Sanga, C. (2007). New technologies for teaching and learning: Challenges for higher learning institutions in developing countries. International Journal of Education and Development using ICT, 3(2).

Singh, G. (2011). An online abstract mentoring programme for junior researchers and healthcare professionals. Distance Education, 32(2), 229-242.

Tam, M. (2000). Constructivism, instructional design, and technology: Implications for transforming distance learning. Educational Technology \& Society, 3(2). Retrieved from http://www.ifets.info/journals/3 2/tam.html

Veletsianos, G. (2010). A definition of emerging technologies for education. In G. Velestianos (Ed.), Emerging technologies in distance education (pp. 1-22). Edmonton, AB: AU Press.

Wang, Z., Chen, L., \& Anderson, T. (2014). A framework for interaction and cognitive engagement in connectivist learning contexts. The International Review of Research in Open and Distributed Learning, 15(2). 


\section{APPENDIX -The Programme Learning Outcomes}

Upon completion of the programme, you should be able to:

1 Examine the UWC learning context

Assessment Criteria

1.1 Factors characterizing the UWC teaching and learning are identified.

1.2 Roles and departmental responsibilities of TA at UWC are reviewed.

1.3 Principles used in teaching own subject are developed using a variety of credible sources.

2 Design one tutorial learning activity

Assessment Criteria

2.1 The learning activity promotes deep understanding of at least one science concept.

2.2 The learning activity forms part of a module plan/course outline

2.3 Information literacy components are incorporated into the learning activity.

2.4 The learning activity can stimulate students to write academically

2.5 The learning activity can be implemented partially or wholly in an online environment

$3 \quad$ Facilitate learning in the classroom context (role play)

Assessment Criteria

3.1 A teaching session plan is well developed and shows that all resources and arrangements are in place.

3.2 The presentation displays clear and concise communication of facts, concepts, ideas and principles relate to a specific learning area and is consistent with the requirements of that learning area.

4 Mark and Assess student work

Assessment Criteria

4.1 Purposes and uses of different modes of assessment in Higher Education are identified.

4.2 Key issues in designing assessments are examined and applied

4.3 The benefits of using assessment criteria and rubrics are explained.

4.4 Good practice is employed when providing feedback to students.

5 Identify a research problem/ opportunity related to the ECP program

Assessment Criteria

5.1 Autharitative resources are used to address the research problem

5.2 A possible plan of action is formulated

\section{Athabasca University}

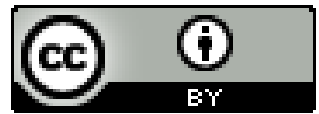

